\title{
Building Leadership: How Pride in Your Work Leads to Better Attendance and Quality
}

\author{
Commentary by Manuel Au-Yong Oliveira
}

\begin{abstract}
Human performance technology (HPT) stresses a rigorous analysis of present and desired levels of performance, identifies the causes of performance gaps, offers a wide range of interventions with which to improve performance, guides the change management process, and evaluates the results. The project described in this article follows this structure, providing evidence supporting the belief that HPT practice leads to superior performance in solving people-related problems.
\end{abstract}

At times, human resource-related problems, such as a lack of trust in management, can lead to all sorts of other maladies. Attendance, quality, and on-time delivery can all be affected, as was the situation in the case illustrated in this article. HPT provides the structure and discipline through which one may move forward, providing a means for management and the front line to get "in tune."

\section{Setting the Scene}

Our founder started out in the 1950s with a loan against his car and only a handful of employees. The company has since developed into a leading diversified metal processing company, with more than 60 facilities around the world and annual sales of approximately US $\$ 2$ billion. Over the last year or so, I have spent a great deal of my time training in the Czech Republic, where our firm acquired a majority interest in a Czech manufacturing company (referred to as Action Company).

This article discusses the means taken to raise attendance and quality to desired levels at Action Company. To create changes in employees' attitudes, we sought to instill pride in the people, demonstrating a symbiotic relationship between the interests of our company and employees' own goals. Action Company, now part of an American multinational company, also had to believe that people are the firm's most important asset.

I was already known and trusted by the local management team at Action Company when I was called in by the international managing director with reports of serious customer complaints.

When we looked at the evidence shown to us by our customers, it became clear that something had to be done or we risked losing our main clients. With several of our manufactured products, serious quality breaches had occurred-faulty products had made it through our lines and on to major automotive accounts, as well as to other players in the steel industry. Even worse than losing customers was the knowledge that someone might become injured due to our lack of a quality product. Immediate action was required.

\section{The Performance Gap}

Action Company had the following objectives prior to the change initiative:

- To become a recognized quality supplier of manufactured steel products, with customers around the globe.

- To have dedicated employees totally committed to the customer.

- To achieve $100 \%$ on-time delivery.

- To have absenteeism levels at or below $2 \%$.

With absenteeism at $8 \%$, the company goal of $2 \%$ was being vastly exceeded. And the high external reject rate was indicative of quality problems that led to customer dissatisfaction $(2,500$ 
parts per million were rejected monthly). This latter point was seen to be connected to a lack of ownership of the production process, as well as to old machinery.

The problems we encountered were thought to be due to cultural aspects particular to Eastern Europe. There was a lack of ownership of the production process, and many employees did not feel they were an essential or active part of the solution to problems. As a former communist nation, the culture was typified by the attitude that people work by following orders. This mindset was detrimental to the performance of Action Company.

Confrontation in order to solve problems is also not a common cultural trait. Many employees preferred smoothing-over and avoidance techniques to solve conflict, as opposed to working toward a solution that integrates the best interests of all parties involved.

\section{Interventions to Improve Performance}

As a trainer, I was responsible for our training effort to improve Action Company's performance. My mentor (the international managing director) was an experienced manager in our corporation. The involvement of senior management in our interventions was deemed critical. Shop-floor workers had to see that we were taking change seriously. We anticipated that this would lead to a closer relationship between stakeholders at all levels, an essential component if we wanted the bottom-up changes to take place.

From the initial awareness of the quality problem until we passed a Volvo audit (a company known to be very tough on quality), 14 months passed. The process of our interventions and the evaluation of our results are presented below.

Regarding absenteeism, a bonus scheme for promoting attendance was instituted, and the training program also sought to correct the situation through awareness training that stressed the importance of coming to work every day. Quality was addressed through investments in both machinery and the front-line employee attitude (i.e., not to pass rejects down the line and on to the customer). Our greatest moment came when Volvo auditors deemed our company ready to supply them globally - a sign that we could be proud of our progress. This was achieved following another major measure-every quality inspector would place a sticker with his or her name on the final product he or she inspected. This way, any faulty product would be traced back to the individual responsible for it, which instituted a culture of accountability.

\section{The Investment in Training}

Corporate culture dictated that we invest in management and leadership training, issues quite different from the former communist regime's near-exclusive support only for political training aligned with Party ideologies. We believed that management and leadership were crucial and could be taught to everyone in the organization, so long as performers had the right motivation.

I had previously been sent to our head office in the United States to coordinate with our group training director and his team and prepare for the upcoming training sessions. The objective was to train the European facilities in our corporatewide programs.

Management Training. Our corporate culture needed to be understood and assimilated, and this was the starting point. Institutional videos were shown and stories were told that focused on how our company had become successful. Our founder, a legend in America, had been interviewed by television, and a video of this interview was shown; it highlighted values such as how he believed in citizenship and in being a major contributor to society and giving back to the community, in terms of building hospitals and sports arenas for people to enjoy.

Managing and securing enduring change was also an important subject within the training. Other topics were conflict management and how to supervize by providing to others a "ladder" through which they could improve. Group leaders were given clear expectations; being closest to performers on the shop floor, their development was of strategic importance. Role playing during the sessions explored such issues as:

- How does one approach an employee who is not wearing his or her safety glasses on the shop floor? 
- How can tardiness be overcome?

- How can critical information be conveyed at shift change?

-What safety regulations should be followed?

-Why do standard operating procedures need to be in place?

Shop Floor Employee Training. Again, our corporate culture needed to be understood. Thus, ours was made to be companywide training, not only for managers but for front-line employees also. Hidden conflict (made visible at the training sessions) due to operators thinking that they were, for example, underpaid and overworked, dissipated when the operators realized what sort of a company they were working for. Our company and founder were well known for treating employees fairly - a fair day's pay for a fair day's work. Trust in management and in our objectives, to beat the worldwide competition, began to spread. In an economy managed centrally by the state, as had happened in the communist era, overt competition between enterprises didn't exist, so this concept was not easy to grasp. Face-to-face explanations were given to those who needed clarification.

People were allowed to voice their opinions freely. We were all on the same side, whether we were operators from Slovakia or managers from the United States.

Ice-breakers included activities in perfectionism. "Spot the differences" competitions for token prizes against the clock also helped increase the necessary attention to detail.

Not letting faulty products go on to the next internal customer on the line required a special dedication. Participants came to understand what a difference they could make by being leaders in their domains, with attention to detail dictating success.

A customer orientation was developed. Faulty products were brought to the sessions. Operators were incredulous that customers had discovered these. Letters from clients complaining about our products were also read aloud.

The training sessions were evaluated, in writing, by all those who attended. Some were critical of the existing Action Company system and said so. The vast majority, however, stated what had been most meaningful to them. Invariably the open atmosphere was appreciated and led to improved attitudes on the shop floor.

Participants came to look forward to being able to interact one-on-one with senior managers, both American and Czech, who sat in with us, participating in the sessions.

Corporate videos, interactive training sessions with active participation from management, group exercises, and competitions for token prizes all added to the atmosphere of participation by all involved. We didn't want button-pushers; we wanted performers to take charge of their duties and show pride in their work.

Long-standing employees brought in from the United States served to demonstrate by example how traits such as attendance, adaptability, and attitude contributed to the success of this workplace of more than 300 employees.

\section{Results}

Absenteeism, a major problem two years before, is now down to approximately $2 \%$. Consequently, it is no longer necessary to run operations overstaffed to make up for those who would miss work.

At the same time and for the same reasons, the rejection rate came down from 2,500 to 246 parts per million on average (with some months close to zero parts per million). Because we were major suppliers to the automotive industry, and specifically Volvo, quality had become a critical concern.

No doubt because pride and perfection are goal oriented, we exceeded customer expectations and added to customer satisfaction - cleaner work stations, standardized operating procedures, operators knowing exactly what project they are working on, defective products reduced to a minimum, and increased on-time delivery. 
Be it a simple job on the line or a seemingly more important management role, we had to want to be quality inspectors for our internal customers, all the way through the factory. Faulty products become more expensive the further they are allowed to travel in the production process. If a faulty weld is caught before the part is painted, all the better. Similarly, if a faulty paint job is caught before the part is finished, we again save resources.

Our CEO communicated the importance of using every possible channel available to us (meetings, training sessions, annual reports, newsletters, international senior management visits, management communiqués) to achieve far-reaching change. Trust between management and the shop floor grew as the people came to realize that we had common goals. By collaborating rather than fighting against one other, our greatest victories emerged: trust in management. In turn, our customers felt our progress and responded by giving us more business.

Amid turbulent competition, our only dependable advantage is to maintain a superior capacity to produce even more change, from the shop floor, where leadership is most needed, upward.

We discovered that a winning attitude is indeed the result of continued dedication over a steady period, with challenging but reachable goals set out. We were finally "in the zone," that state that athletes most notably enter, where everything seems to flow effortlessly.

But we did know how hard it really had been to get there. 